\title{
Imiquimod-associated erythema multiforme
}

\author{
Katarina Trčko ${ }^{1 凶}$ \\ ${ }^{1}$ Department of Dermatology, Maribor University Clinical Center, Maribor, Slovenia.
}

\begin{abstract}
Patients with multiple actinic keratoses are frequently treated with topical agents such as imiquimod, an immune-response modifying agent. Adverse effects associated with imiquimod therapy are mainly limited to the application site and include erythema, crusting, scaling, and ulceration. Systemic adverse reactions such as erythema multiforme are rare. Here we report a case of a 77-year-old patient that developed erythema multiforme after treatment of actinic keratoses with imiquimod. Cessation of imiquimod and treatment with local corticosteroids led to rapid regression of erythema multiforme lesions. Residual actinic keratoses were treated with cryotherapy.
\end{abstract}

Keywords: cutaneous adverse drug reaction, topical immunomodulators, malignant epithelial tumors

Received: 13 January 2020 | Returned for modification: 15 February 2020 | Accepted: 15 March 2020

\section{Introduction}

Erythema multiforme is an acute, immune-mediated, self-limited disorder triggered by certain infections, medications, or other various agents. It is considered a type IV hypersensitivity reaction and it is characterized by symmetrically distributed targetoid lesions that can be accompanied by mucosal erosions $(1,2)$. The most common causes are herpes simplex virus (HSV) and Mycoplasma pneumoniae infection $(3,4)$. Systemic drugs are the second most frequent causative agents (1). Topical drugs rarely cause erythema multiforme or erythema multiforme-like reactions (5). Here we report the case of a 77-year-old patient that developed erythema multiforme after treatment of actinic keratoses with imiquimod.

\section{Case report}

A 77-year-old man with light skin presented with a 4-year history of persistent scaly papules and plaques on his bald head. In the past he was diagnosed with actinic keratoses and was treated once with cryotherapy. He was otherwise healthy. On physical examination, pigmented thickened papules and plaques with a scaly surface were found. Based on clinical appearance, a diagnosis of actinic keratoses was made. We prescribed him 5\% imiquimod cream and he started applying the cream three times per week to the affected skin. After 3 weeks a prominent local reaction developed at the application site and new lesions appeared on the upper extremities, back, and lips. On physical examination, symmetrically distributed round macules, some with central vesicles on the upper extremities and neck, erosions on the lips, and hyperkeratotic crusts on his scalp were found (Figs. 1-4). A physical examination revealed no further anomalies. Histopathological examination of a skin lesion specimen from the upper extremity showed keratinocyte necrosis with the formation of intraepidermal gap under necrosis and interface dermatitis with an inflammatory, predominantly lymphohistiocytic infiltrate in the papillary dermis (Fig. 5). Polymerase chain reaction (PCR) for HSV-1 and HSV-2 from a swab of a lip lesion was negative.

Based on the clinical features and histopathological findings, a diagnosis of erythema multiforme was made. Because other common causes for erythema multiforme were ruled out, we concluded that imiquimod was the most likely cause. Therapy with imiquimod was stopped. The patient was treated with topical corticosteriod cream, and after 20 days of therapy all erythema multiforme lesions disappeared. Residual actinic keratoses were treated with cryotherapy.

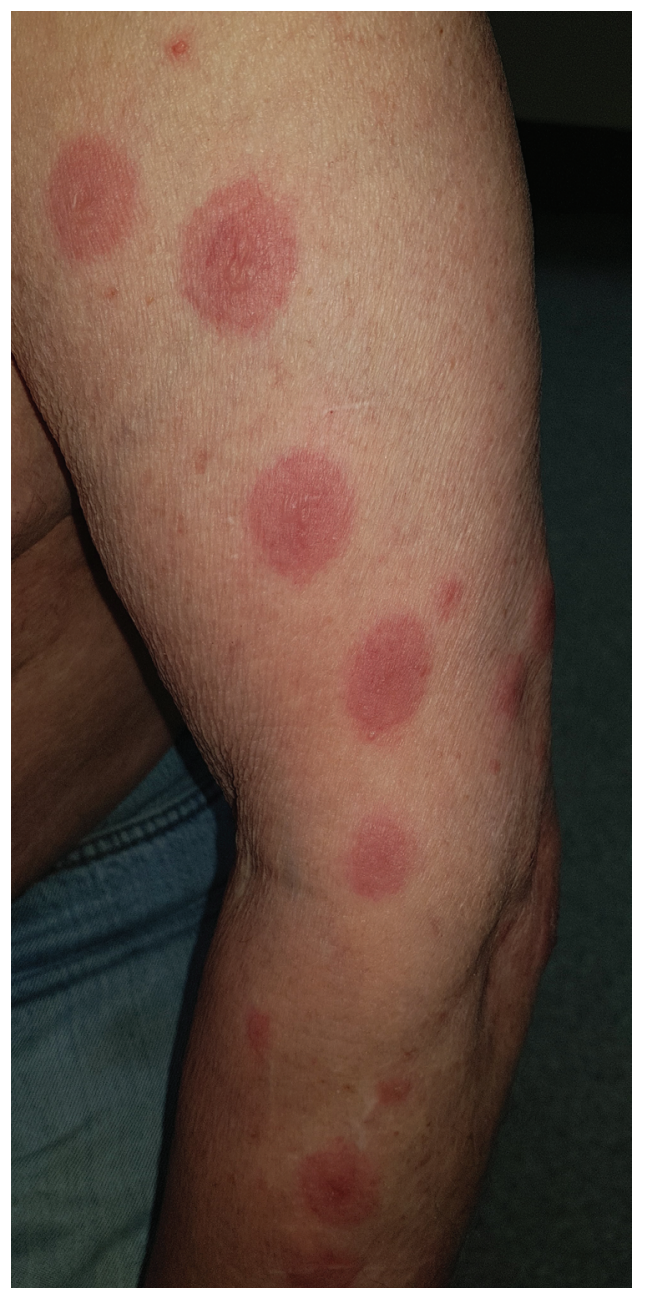

Figure 1| Targetoid lesions distributed symmetrically on the upper extremities. 


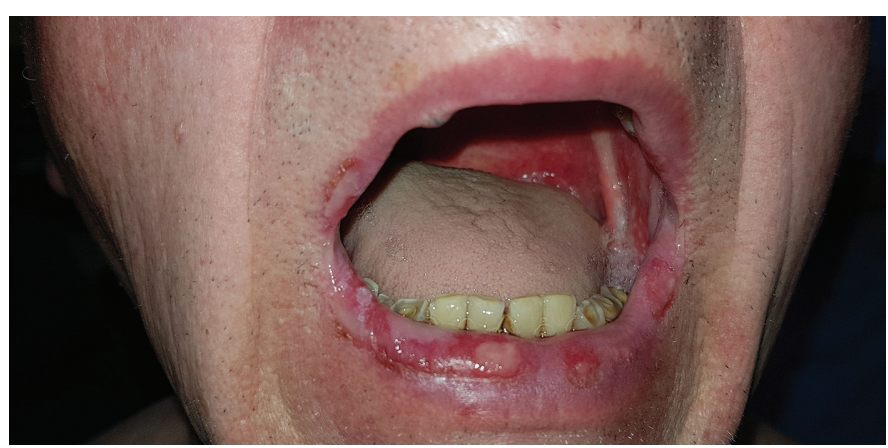

Figure 2 | Mucosal erosions.

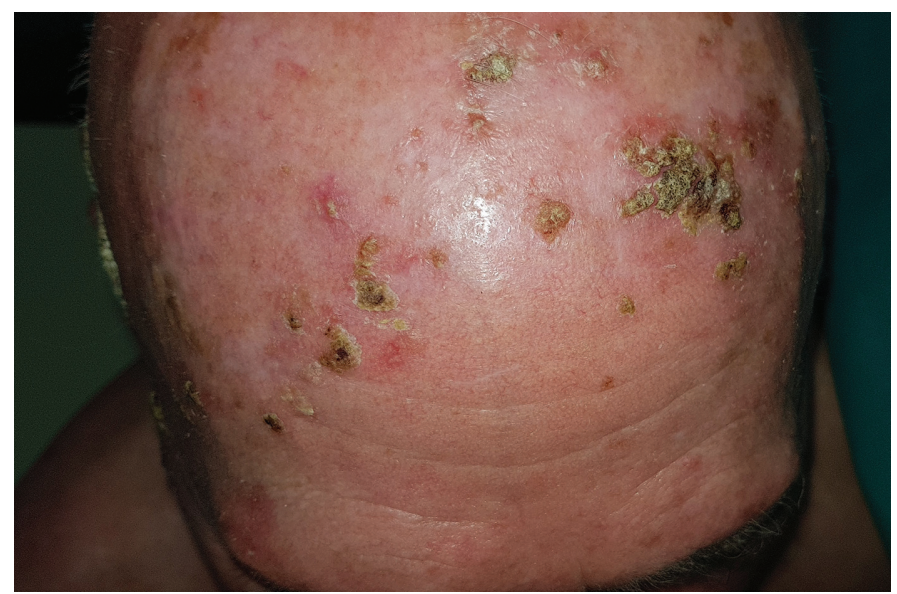

Figure 3 | Moderate inflammation with erythema and crusting on the scalp.

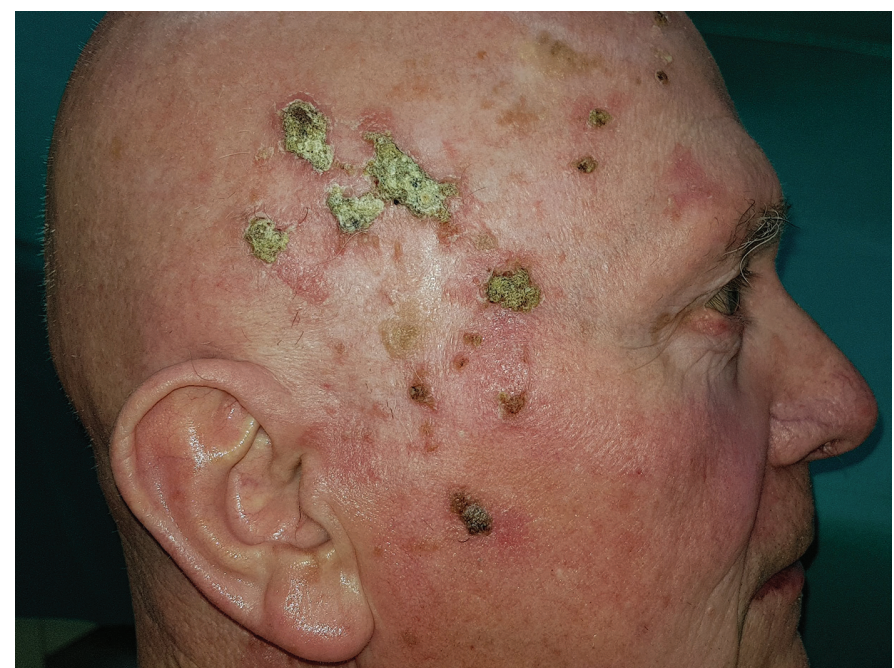

Figure 4 | Moderate inflammation with erythema and crusting on the scalp.

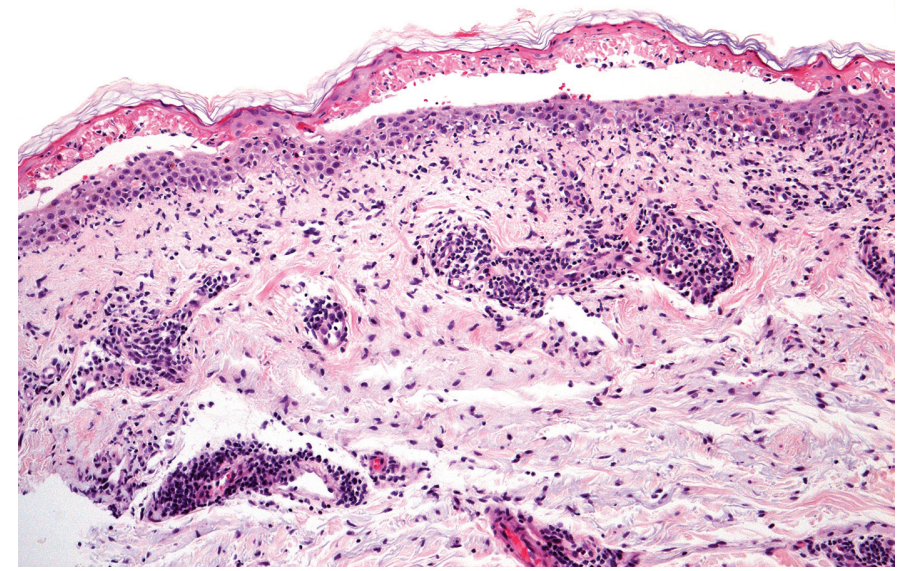

Figure 5 | Intraepidermal blistering with completely necrotic roof of the blister, marked apoptosis and hydropic degeneration of the basal cell layer.

\section{Discussion}

Imiquimod is approved for the treatment of actinic keratoses, superficial basal cell carcinomas, and genital warts. It activates both the innate and the acquired immune system (6). Through stimulation of toll-like receptor 7 on the surface of antigen-presenting cells, imiquimod induces the production and secretion of various proinflammatory and antimicrobial cytokines, such as interferon- $a$ and $-y$, tumor necrosis factor- $a$, and interleukins 1 , $6,8,10$, and 12, resulting in stimulation of T-helper 1 cells and cytotoxic T lymphocytes $(7,8)$. Clinically, this reaction manifests itself with acute local inflammation, which leads to elimination of cells with neoplastic changes, as well as virus-infected cells. The intense local reaction may result in a better treatment outcome (9). There have been reports of rare adverse cutaneous effects after imiquimod therapy, such as aphthous ulcers, eczema, alopecia, hyperpigmentation, vitiligo-like pigmentation, subacute cutaneous lupus erythematosus, pemphigus foliaceus, pemphigus vulgaris, linear IgA bullous dermatosis, eruptive epidermoid cysts, keratoacanthoma, lichen planus, lichen sclerosus, psoriasis-like dermatitis, angioedema, urticaria, morbilliform exanthema in an immunosuppressed patient, and lymphoedema (10-26). Other dermatological disorders associated with imiquimod are exacerbation of previous dermatoses such as psoriasis and pityriasis rubra pilaris $(27,28)$.

Frequent systemic adverse reactions include flu-like symptoms, fever, arthralgia, or myalgia (29). The systemic adverse effects are probably due to systemic cytokine release because imiquimod absorption is minimal across intact skin $(29,30)$. Only a few cases of erythema multiforme due to imiquimod have previously been reported (31-36). The pathogenesis of erythema multiforme is not fully understood. Current evidence suggests that it is most likely the result of cell-mediated immune reactions that occur in the setting of various triggering factors, including drugs in predisposed individuals $(37,38)$.

After reviewing the literature, the majority of patients with erythema multiforme due to imiquimod developed intense local inflammation at the application site. It has been hypothesized that the absorption of imiquimod through very inflamed skin may have been greater than expected from earlier studies and that the application of the drug to skin wounds, mucous membranes, or skin with impaired barrier function may enhance the risk of a serious systemic reaction, such as Stevens-Johnson syndrome, toxic epidermal necrolysis, and anaphylaxis $(39,40)$. It has been speculated that systemic absorption of the drug and a subsequent type III or IV hypersensitivity reaction lead to development of erythema multiforme $(34,37)$. In our patient, local inflammation was mild to moderate, and no systemic symptoms were observed. Thus, the development of erythema multiforme in our patient could be related to the large treatment area and possible systemic absorption of the drug.

To conclude, in the reported case the patient developed erythema multiforme in the setting of imiquimod treatment. Clinicians should be aware of this rare but serious adverse effect. Patients with extensive actinic keratoses or intense local inflammation may have a greater risk of developing erythema multiforme. 


\section{References}

1. Lerch M, Mainetti C, Beretta-Piccoli BT, Harr T. Current perspectives on erythema multiforme. Clinical Rev Allerg Immunol. 2018;54:177-84.

2. Sokumbi 0, Wetter DA. Clinical features, diagnosis, and treatment of erythema multiforme: a review for the practicing dermatologist. Int J Dermatol. 2012;51: 889-902.

3. Huff JC, Weston WL, Tonnesen MG. Erythema multiforme: a critical review of characteristics, diagnostic criteria, and causes. J Am Acad Dermatol. 1983;8:763-75.

4. Schalock PC, Dinulos JG, Pace N, Schwarzenberger K, Wenger JK. Erythema multiforme due to Mycoplasma pneumoniae infection in two children. Pediatr Dermatol. 2006;23:546-55.

5. Griffiths C, Barker J, Bleiker T, Chalmers R, Creamer D. Rook's textbook of dermatology, 9th ed. Hoboken, NJ: Wiley-Blackwell; 2016. Chapter 47, Reactive inflammatory erythemas; $\mathrm{p}$. 47.1-17.

6. Hengge UR, Benninghoff B, Ruzicka T, Goos M. Topical immunomodulators-progress towards treating inflammation, infection, and cancer. Lancet Infect Dis. 2001;1:189-98.

7. Vidal D, Alomar A. Mode of action and clinical use of imiquimod. Expert Rev Dermatol. 2008;3:151-9.

8. Sauder DN. Imiquimod: modes of action. Br J Dermatol. 2003;149:5-8.

9. Stockfleth E, Sterry W, Carey-Yard M, Bichel J. Multicentre, open-label study using imiquimod $5 \%$ cream in one or two 4 -week courses of treatment for multiple actinic keratoses on the head. Br J Dermatol. 2007;157:41-6.

10. Chakrabarty AK, Mraz S, Geisse JK, Anderson NJ. Aphthous ulcers associated with imiquimod and the treatment of actinic cheilitis. J Am Acad Dermatol. 2005; 52:35-7.

11. Taylor CL, Maslen M, Kapembwa M. A case of severe eczema following use of imiquimod 5\% cream. Sex Transm Infect. 2006;82:227-8.

12. Conde J, Davis K, Ntuen E, Balmer N, Jones D, McMichael A. A case of imiquimodinduced alopecia. J Dermatolog Treat. 2010;21:122-4.

13. Berman B, Kaufman J. Pilot study of the effect of postoperative imiquimod $5 \%$ cream on the recurrence rate of excised keloids. J Am Acad Dermatol. 2002;47: 209-11.

14. Brown T, Zirvi M, Cotsarelis G, Gelfand JM. Vitiligo-like hypopigmentation associated with imiquimod treatment of genital warts. J Am Acad Dermatol. 2005;52: 715-6.

15. Burnett TJ, English JC 3rd, Ferris LK. Development of subacute cutaneous lupus erythematosus associated with the use of imiquimod to treat actinic keratoses. J Drugs Dermatol. 2010;9:1022-4.

16. Lin R, Ladd DJ Jr, Powell DJ, Way BV. Localized pemphigus foliaceus induced by topical imiquimod treatment. Arch Dermatol. 2004;140:889-90.

17. Bauza A, Del Pozo LJ, Saus C, Martin A. Pemphigus-like lesions induced by im iquimod. Clin Exp Dermatol. 2009;34:e60-e62.

18. Tadiotto Cicogna G, Ferranti M, Vaccari D, Alaibac M. Topical imiquimod-induced linear IgA bullous dermatosis. BMJ Case Rep. 2019;19;12.

19. Marty CL, Randle HW, Walsh JS. Eruptive epidermoid cysts resulting from treatment with imiquimod. Dermatol Surg. 2005;31:780-2.

20. D’Addario S, Carrington PR. Multiple keratoacanthomas as an untoward response to imiquimod therapy for actinic keratoses. Acta Derm Venereol. 2006;86:366-7.

21. O'Mahony C, Yesudian PD, Stanley M. Imiquimod use in the genital area and development of lichen sclerosus and lichen planus. Int J STD AIDS. 2010;21:219-21.
22. Gilliet M, Conrad C, Geiges M, Cozzio A, Thürlimann W, Burg G, et al. Psoriasis triggered by toll-like receptor 7 agonist imiquimod in the presence of dermal plasmacytoid dendritic cell precursors. Arch Dermatol. 2004;140:1490-5.

23. Jacobs AA, Snavely N, Markus J, Rosen T. Vasodilatory adverse events associated with topical imiquimod 5 percent cream. DOJ. 2008;14:4

24. Barton JC. Angioedema associated with imiquimod. J Am Acad Dermatol. 2004; 51:477-8.

25. Cavicchini S, Vezzoli P, Muratori S, Gianotti R. Morbiliform exanthem induced by imiquimod in a patient with drug-related immunosuppression. Clin Exp Dermatol. 2009;34:526-7.

26. Tio D, Kirtschig G, Hoekzema R, van Montfrans C. Lymphoedema in patients with lentigo maligna treated with imiquimod: a long-term adverse effect. $\mathrm{Br} J$ Dermatol. 2018;178:1441-2.

27. Patel U, Mark NM, Machler BC, Levine VJ. Imiquimod $5 \%$ cream induced psoriasis: a case report, summary of the literature and mechanism. $\mathrm{Br}$ J Dermatol. 2011;164:670-2.

28. Leite OG, Tagliolatto S, Souza EM, Cintra ML. Acantholytic pityriasis rubra pilaris associated with topical use of imiquimod $5 \%$ : case report and literature review. An Bras Dermatol. 2020;95:63-6.

29. Food and Drug Administration. (October 2010). Aldara $®$ (imiquimod) cream, $5 \%$ : highlights of prescribing information. [Internet]. Available from: https://www.accessdata.fda.gov/drugsatfda_docs/label/2010/0207235022lbl.pdf.

30. Garcia-Arpa M, Rodriguez-Vazquez M, Delgado Portela M, Vera Iglesias E. Erythema multiforme due to imiquimod 5\% cream. Actas Dermosifliogr. 2010;101 $551-2$.

31. Christou E, Morrow C. Erythema multiforme to topical imiquimod $5 \%$ cream. Australas I Dermatol. 2012;53:32.

32. Ballester I, Guijarro J, Niveiro M. Erythema multiforme induced by imiquimod $5 \%$ cream. Int J Dermatol. 2014;53:347-8.

33. Yanes DA, Kaffenberger JA, Carr DR. Erythema multiforme as a reaction to imiquimod 5\% cream. Dermatol Online J. 2017;23:18.

34. Chan M, Kennedy J, Oakley A. Erythema multiforme triggered by imiquimod $5 \%$ cream. Australas J Dermatol. 2017:58:257-8.

35. Peña-López S, Suárez-Magdalena O, Monteagudo B, Cabanillas M. Erythema multiforme caused by treatment with topical imiquimod $5 \%$ in a patient with Gorlin syndrome. Actas Dermosifiliogr. 2018;109:277-8.

36. Maxfield L, Gaston D, Peck A, Hansen K. Topical imiquimod and subsequent erythema multiforme. J Am Osteopath Assoc. 2020;120:45-8.

37. Bolognia JL, Schaffer JV, Cerroni L. Dermatology. 4th ed. Edinburgh: Elsevier; 2018. Chapter 20, Erythema multiforme, Stevens-Johnson syndrome, and toxic epidermal necrolysis; p. 332-47.

38. Schofield JK, Tatnall FM, Brown J, McCloskey D, Navarrete C, Leigh IM. Recurrent erythema multiforme: tissue typing in a large series of patients. $\mathrm{Br}$ J Dermatol. 1994;131:532-5.

39. Harrison LI, Skinner SL, Marbury TC, Owens ML, Kurup S, McKane S, et al. Pharmacokinetics and safety of imiquimod $5 \%$ cream in the treatment of actinic keratoses of the face, scalp, or hands and arms. Arch Dermatol Res. 2004;296:6-11.

40. Hanger C, Dalrymple J, Hepburn D. Systemic side effects from topical imiquimod. N Z Med J. 2005;118:U1682. 